\title{
Mechanistic Studies of Gravity-Assisted Water Flooding in a Thick Heavy Oil Reservoir through Horizontal Injectors Using Three-Dimensional Physical Model
}

\author{
Debin Kong, ${ }^{1}$ Chao Wang, ${ }^{2}$ Fei Zhou, ${ }^{2}$ Yiqiang Li, ${ }^{1}$ Ruicheng Ma, ${ }^{1}$ and Qinghui Zhao ${ }^{3}$ \\ ${ }^{1}$ Enhanced Oil Recovery Institute, China University of Petroleum, No. 18 Fuxue Road, Beijing 102249, China \\ ${ }^{2}$ PetroChina Tarim Oilfield Company, Korla 841000, China \\ ${ }^{3}$ Exploration \& Development Research Institute, Liaohe Oilfield Ltd. Co., Panjin, Liaoning 124010, China \\ Correspondence should be addressed to Yiqiang Li; lyq89731007@163.com
}

Received 29 April 2016; Revised 14 July 2016; Accepted 18 August 2016

Academic Editor: Gerardo Severino

Copyright ( 2016 Debin Kong et al. This is an open access article distributed under the Creative Commons Attribution License, which permits unrestricted use, distribution, and reproduction in any medium, provided the original work is properly cited.

\begin{abstract}
Laboratory experiments were conducted to investigate the mechanism(s) of water flood with horizontal injection wells. The experiment was performed using a three-dimensional (3D) physical model made by artificial sandstone of the dimension of $60 \mathrm{~cm} \times 30 \mathrm{~cm} \times 5 \mathrm{~cm}$. The saturation profile of oil and water phases was monitored by measuring the electrical resistivity using microelectrodes. It is difficult to model a field-scale gravity-assisted water flood process in the laboratory as the gravity force is very small in the physical model. In this paper, similarity criteria, dimensional analysis, and $\pi$ principle were used to design the model parameters. We found that the ratios of gravity force to production pressure differential, capillary force, and viscous force are the three most important similarity criteria. Based on dimensional analysis, both capillary and viscous forces were designed in the physical model to represent the capillary and bond number in the reservoir conditions. Hence, in physical model, rock permeability of 6 darcies was selected to reduce the capillary force and the fluid viscosity of $583 \mathrm{cp}$ was selected to reduce the viscous force based on calculation. The use of horizontal injection well can improve the sweep efficiency by $17.2 \%$, compared with the case of vertical injection well. To determine the optimal driving force, the ratio of gravity force and production pressure differential was varied from $1: 1$ to $1: 16$. The experiment has shown that the ratio of $1: 8$ yields the highest heavy oil recovery $(44.04 \%)$.
\end{abstract}

\section{Introduction}

Water flood provides a main driving mechanism to recover the oil, which is simple, inexpensive secondary recovery process and is being widely used. Applications of horizontal wells in water flooding as injectors and/or producers continue to grow. The horizontal wells have been shown to improve the ultimate oil recovery over that of conventional vertical wells during a regular water flood and enhanced oil recovery (EOR). More attention has been given recently to investigate how horizontal wells contribute to ultimate oil recovery in these processes.

Hovanessian and Fayers [1] found that gravity had a pronounced effect on the saturation profile and the pressure distribution curves using horizontal injectors. Numerical simulation was carried out in the study of the hybrid system of vertical producers and horizontal injectors by Cunningham and Chaliha [2]. It was found that the horizontal wells added little benefit of sweep volume in the lower unit. However, there was no study of benefits of horizontal injections in an areal pattern. Al Gharaib and Gharbi [3] used numerical method to investigate a part of the nine-spot pattern where the horizontal wells were used as injectors. Their results showed that the hydrocarbon recovery from the nine-spot pattern was related to the lateral aspect ratio. Meanwhile, the long horizontal wells did not guarantee an improved oil recovery. As to physical model used in laboratory study, Ferreira et al. [4] conducted the studies in the 2D and 3D physical models which were similar to a 5-spot well pattern in a 40-acre spacing. In their pioneering study, the oil-water mobility ratio was designed to be from 1 to 10 . This oil viscosity is too low to fit the scenario existing in the heavy 
oil reservoir. Although Ferreira et al. [4] studied the pressure profile and the displaced oil volume, they failed to monitor the fluid saturation in their model.

Very few researchers have investigated the effect of horizontal wells on water flooding of heavy oil reservoirs. Cao et al. [5] studied the dimensionless height without perforation and the perforation length in horizontal segment, with some optimization results for five-spot and nine-spot system using numerical simulation under the conditions in heavy oil reservoirs, which was related to the type of injection system, horizontal length of horizontal wells, and the position for perforation. Based on the field test conducted in LiaoHe oilfield in Liaoning province, Ding [6] concluded that the gravity-assisted lateral water flooding would tap the potential of the remaining oil with the energy supplement in the upper segment of the heavy oil reservoir.

The formation of interest in this study is called Block A, which is a part of positive rhythm thick heavy oil reservoir. There is enrichment of remaining oil between the top of the reservoir and the well after water flooding and steam huff and puff [7-10]. Horizontal wells at the top of reservoir are being put forward to resolve the problems existing in Block A development process and remaining oil distribution. After placing a vertical production well at the bottom and a horizontal injection well at the top, the remaining oil can be produced with the aid of the gravity of thick oil layer. Horizontal injection well has advantages of low injection pressure and large injection volume, and especially it can improve the sweep efficiency [11, 12]. The gravity in thick reservoir contributes to the enhancement of vertical seepage velocity, which makes oil and water exchange sufficiently. It also enlarges the swept area of reservoir longitudinally and then improves reservoir development effect. Therefore, we can use the dual advantages of the horizontal well and the gravity to explore this part of the remaining oil and reach the purpose of improving oil recovery.

In order to clearly define the contributions of different driving mechanisms involved in this gravity-assisted water flooding process in thick heavy oil reservoir, a more practical and innovative physical simulation system is required. Similarity criteria were introduced in the mechanistic study of the physical model. Meanwhile, the paper presents the contours of the oil saturation in the three-dimensional model, which is calculated using the real-time data from the electrical resistivity monitoring system. Furthermore, an optimization of the injection parameters was performed by this new approach to physical simulation method, which is forwardlooking and innovative.

\section{The Monitoring of Movable Fluid Saturation by Measuring the Electrical Resistivity}

Electrical conduction is assumed not to be present within the rock grains or in fluids other than water. The relationship between water saturation and resistivity is depicted by Archie Equation (1), which is typically valid for shale-free clean formation. Hence, the evaluation of water saturation becomes possible when we measure the resistance change along the core sample during a water flood.

The greater the concentration of formation water in the rock is, the smaller the resistance between the inlet and outlet faces of the rock will be [13-15]. Therefore, the reservoir electrical property can be used to evaluate the change of water saturation. When the porosity and water salinity are constant, the resistivity index " $I$ " is only dependent on oil and water saturation, which is

$$
I=\frac{R_{t}}{R_{0}}=S_{w}^{-n}
$$

where $R_{t}$ is the resistivity of rock sample with a certain saturation and oil, gas, and water;

$R_{0}$ is the resistivity of rock sample with $100 \%$ water saturation;

$S_{w}$ is the saturation of formation water in the rock;

$n$ is saturation exponent.

The change of oil and water saturation was monitored by measuring the electrical resistance in a real-time manner. As shown in Figure 1, the saturation monitoring system is made up of microelectrode, transmission cable, digital output board, and $\mathrm{A} / \mathrm{D}$ conversion interface board and computer. The electrical properties in the core flow physical model can be measured from the different points simultaneously in a real-time manner. In the displacement-type experiment in $3 \mathrm{D}$ physical model, the data acquisition system monitors the change of resistivity in different points and layers, and the data can be used to determine the distribution of oil and water saturation and water front.

In order to accurately determine the changes of water saturation, we have established the relationship between resistance value and water saturation in a $1 \mathrm{D}$ core flood model [16]. We injected different ratios of oil and water $(4: 1,3: 2$, $4: 3,1: 1,3: 4,2: 3,1: 2$, and $1: 5)$ into the $1 \mathrm{D}$ model and then measured the resistance value under different water saturation. We then obtained the relationship of resistance and water saturation, as shown in Figure 2.

Using the established correlation, we can further calculate the oil saturation in the sample by measuring the resistance and obtain the oil saturation of the model in different locations and different time points during the core flood.

\section{Three-Dimensional Physical Model and Simulation Experiments}

3.1. Model Parameter Selection from Similarity Criteria. Based on two-phase mathematical model considering gravity and capillary force, we derived the gravity similarity criterion for a water flood from the top of the reservoir using horizontal wells, with the aid of dimensional analysis method and Buckingham $\pi$ theorem, as shown in Table $1[17,18]$.

As depicted in Table 1, three $\pi$ terms represent the contribution of four forces (gravity force, driving force, capillary force, and viscous force) in the reservoir which 


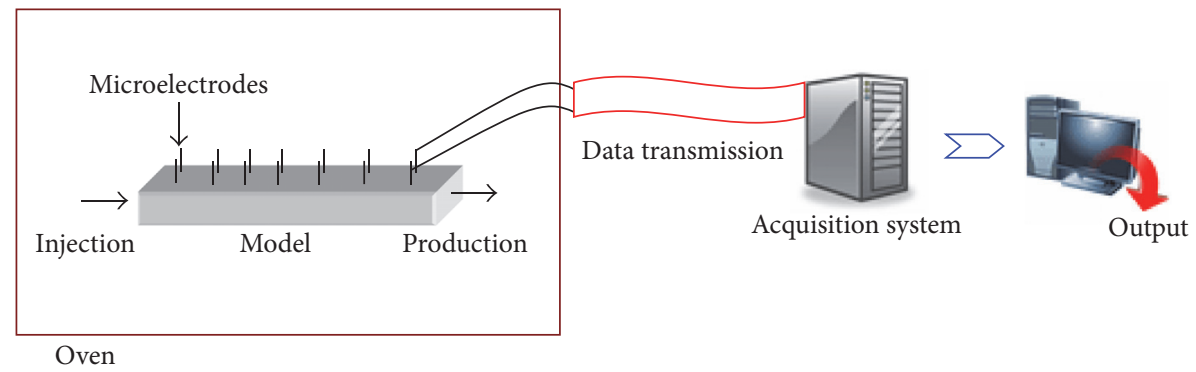

(a)

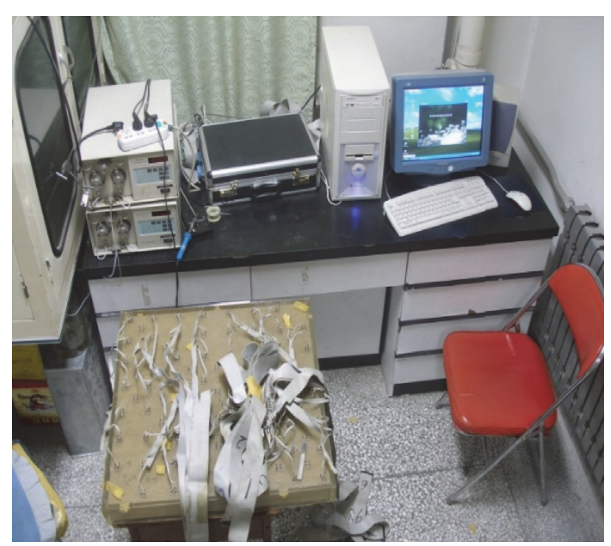

(b)

Figure 1: (a) The diagram of core flow setup and data acquisition system. (b) The actual saturation measurement system and physical simulation model.

TABLE 1: Dimensionless groups used in horizontal wells reservoir and their physical meanings.

\begin{tabular}{lcc}
\hline Number & Dimensionless groups $(\pi$ terms $)$ & Physical meanings \\
\hline 1 & $\pi_{1}=\Delta \rho g H / \Delta P$ & The ratio of the gravity to driving force \\
2 & $\pi_{2}=\Delta \rho g H / p_{c}$ & The ratio of the gravity to capillary force \\
3 & $\pi_{3}=K \Delta \rho g / \mu v$ & The ratio of the gravity to viscous force \\
\hline
\end{tabular}

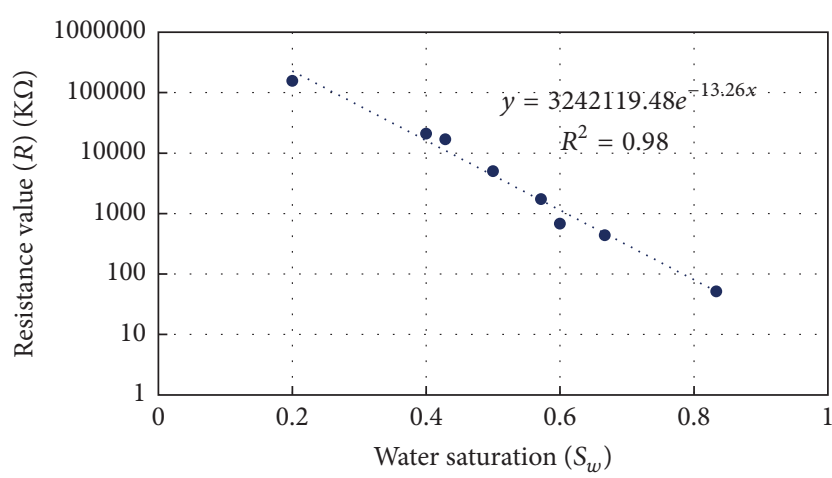

FIGURE 2: The correlation of resistance and water saturation.

influence the distribution of oil and water phases. From similarity criterion sensitivity analysis, we found that $\pi_{1}$ and $\pi_{2}$ have the larger impact on the development of oil field using the horizontal injection well at the top of thick oil layer. They are the main factors controlling the oil and water distribution longitudinally.
TABLE 2: Permeability and capillary force of the core.

\begin{tabular}{lc}
\hline Permeability $\left(10^{-3} \mu \mathrm{m}^{2}\right)$ & Capillary force $p_{c 50}(\mathrm{MPa})$ \\
\hline 139 & 1.2 \\
1700 & 0.0617 \\
2700 & 0.0492 \\
6000 & 0.00126 \\
\hline
\end{tabular}

Based on the similarity criterion of $\pi_{1}, \pi_{2}$, and $\pi_{3}$ as described above, we have designed and selected the size of the experimental model, the rock permeability, the injection rate, and the viscosity of crude oil. Table 2 shows the relationship between rock intrinsic permeability and capillary pressure $p_{c 50}$ ( $p_{c 50}$ represents the capillary pressure when mercury injection saturation is $50 \%$ on the intrusive mercury injection curve) from the routine core analysis. As expected, with the increase of the sample permeability, the capillary force $p_{c 50}$ is reduced. Therefore, we can select a sample with reasonable capillary force by inferring from the rock permeability. We have summarized all the critical parameters involved in the 
TABLE 3: The comparison of parameters for reservoir property and physical model.

\begin{tabular}{lcr}
\hline Parameters & Reservoir & Experimental model \\
\hline Sample size & $140 \mathrm{~m} \times 70 \mathrm{~m} \times 30 \mathrm{~m}$ & $0.3 \mathrm{~m} \times 0.05 \mathrm{~m} \times 0.6 \mathrm{~m}$ \\
Permeability & $1748 \times 10^{-3} \mu \mathrm{m}^{2}$ & $6000 \times 10^{-3} \mu \mathrm{m}^{2}$ \\
Viscosity of crude oil & $200 \mathrm{mP} \cdot \mathrm{s}$ & $583 \mathrm{mP} \cdot \mathrm{s}$ \\
Injection rate & $2 \mathrm{~m} /$ day & $2.35 \mathrm{~m} /$ day \\
\hline
\end{tabular}

TABLE 4: Comparison of the average recovery factor, the areal sweep efficiency, and the remaining oil saturation in two different injectionproduction well configurations.

\begin{tabular}{lccc}
\hline & Horizontal injection well & Vertical injection well & The difference \\
\hline The remaining oil saturation & 45.08 & 49.61 & 4.53 \\
Water flood sweep efficiency (\% PV) & 71.8 & 54.6 & 17.2 \\
The water flood oil recovery factor (\% OOIP) & 41.78 & 34.16 & 7.62 \\
\hline
\end{tabular}
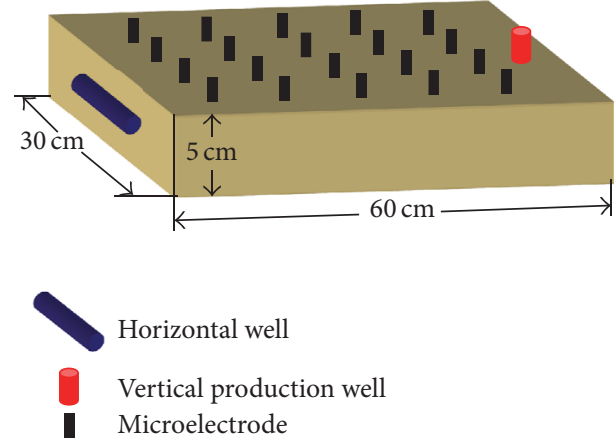

FIGURE 3: Illustration of horizontal well pattern and physical model design.

experimental design based on the similarity criterion of $\pi_{1}$, $\pi_{2}$, and $\pi_{3}$, as shown in Table 3 .

\subsection{Physical Model Experiments}

3.2.1. The Effects of Horizontal Well on the Sweep Efficiency. As suggested by similarity criteria, we have constructed two different physical models: horizontal injection well, vertical production well, and vertical injection well, vertical production wells (the length of horizontal well was $30 \mathrm{~cm}$ and the vertical well was perforated at $3 \mathrm{~cm}$ from top to bottom), as shown in Figures 3 and 4, respectively. The electrodes were arranged uniformly on the model.

We performed water flooding experiment in these two different physical models using constant injection rate of $0.1 \mathrm{~mL} / \mathrm{min}$. The resistance data was acquired in each electrode to monitor the distribution of water saturation and water flooding sweep efficiency.

The oil recovery factor, areal sweep efficiency, and remaining oil saturation in two different injection-production well patterns are summarized in Table 4. The relationship between water cut, cumulative oil recovery, and the cumulative water injection volume is shown in Figure 5.

The experiments results indicate that the oil recovery factor using horizontal injection well is better than that of

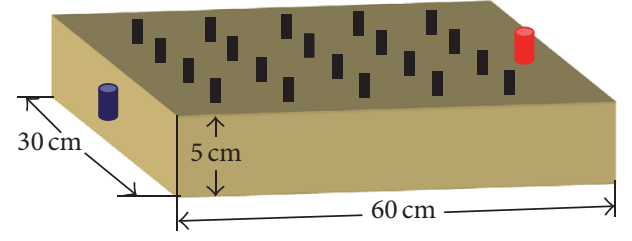

Vertical production well
Vertical injection well
Microelectrode

FIGURE 4: Illustration of vertical injection well pattern and physical model design.

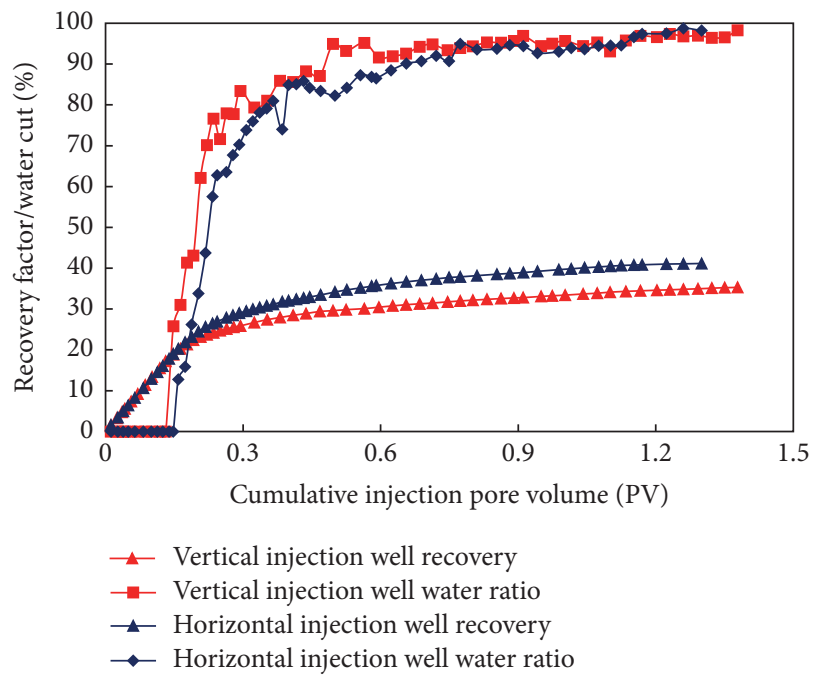

FIGURE 5: The relationship between water cut and recovery factor with cumulative injection pore volume for horizontal and vertical injection well.

vertical injection well. The remaining oil saturation after water flood using horizontal injector is $45.08 \%$, which is less than that of vertical injection well, which is $49.61 \%$. The areal sweep efficiency of horizontal well is $17.2 \%$ larger than vertical 


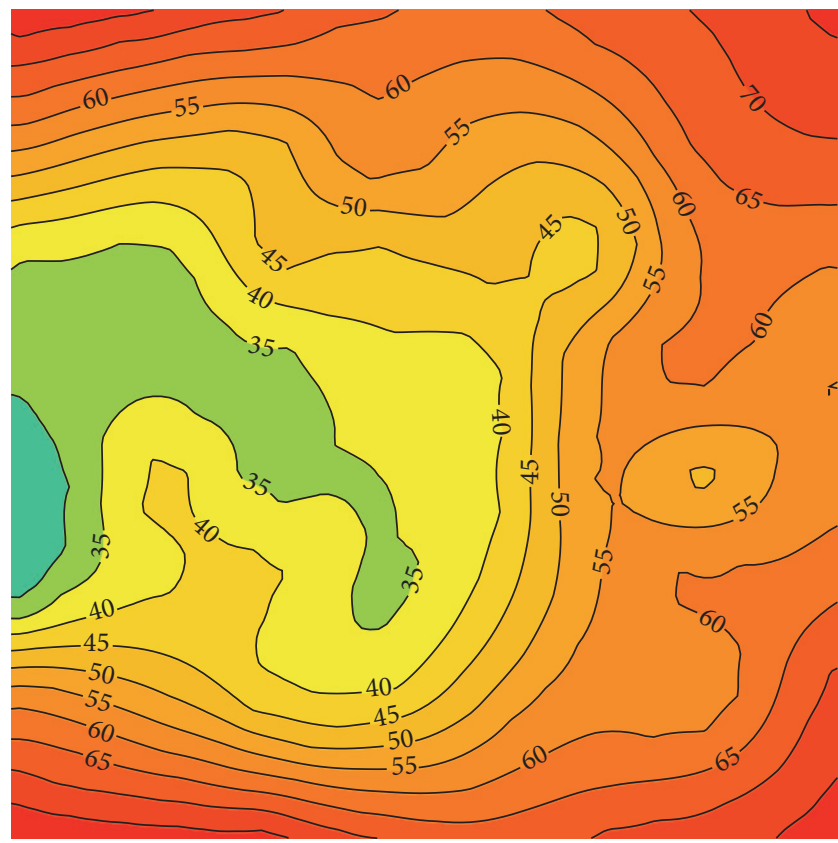

FIGURE 6: Oil saturation distribution after injecting 0.3 PV water through horizontal well.

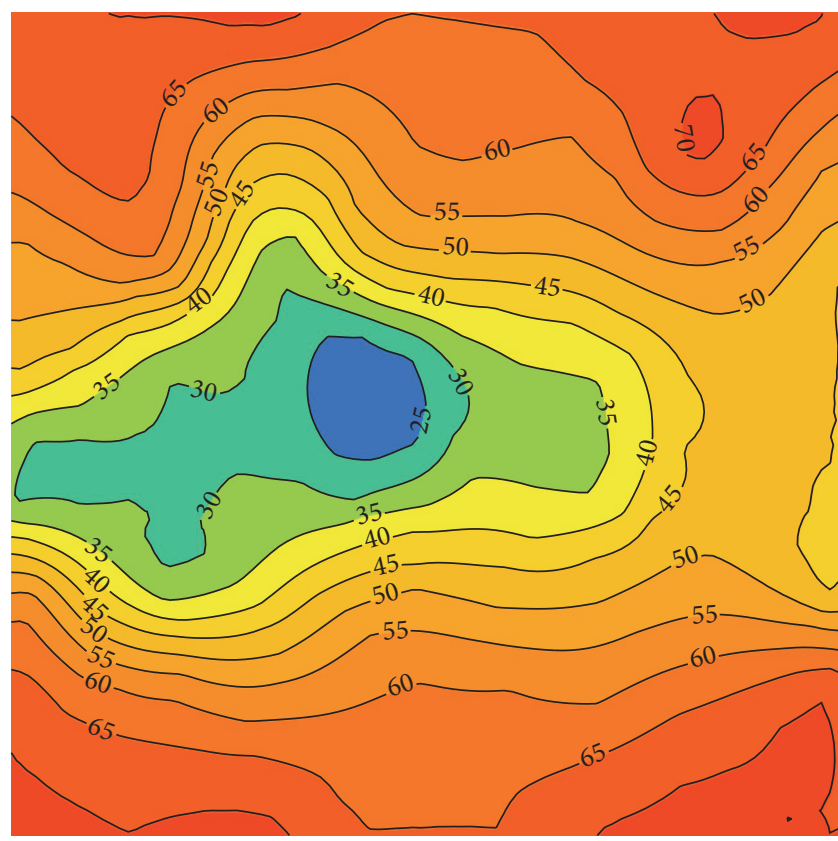

FIGURE 7: Oil saturation distribution after injecting 0.3 PV water through vertical well.

injection well, and the final recovery factor of horizontal injection well is $7.62 \%$ higher than vertical injection well. It implies that horizontal injection well can expand the sweep area, change the fluid flow mode, delay the increase of water cut, and ultimately improve the oil displacement efficiency.

From Figures 6-11, the evolution of oil saturation distribution during a water flood using horizontal or vertical injection well is presented. These figures show that the sweep

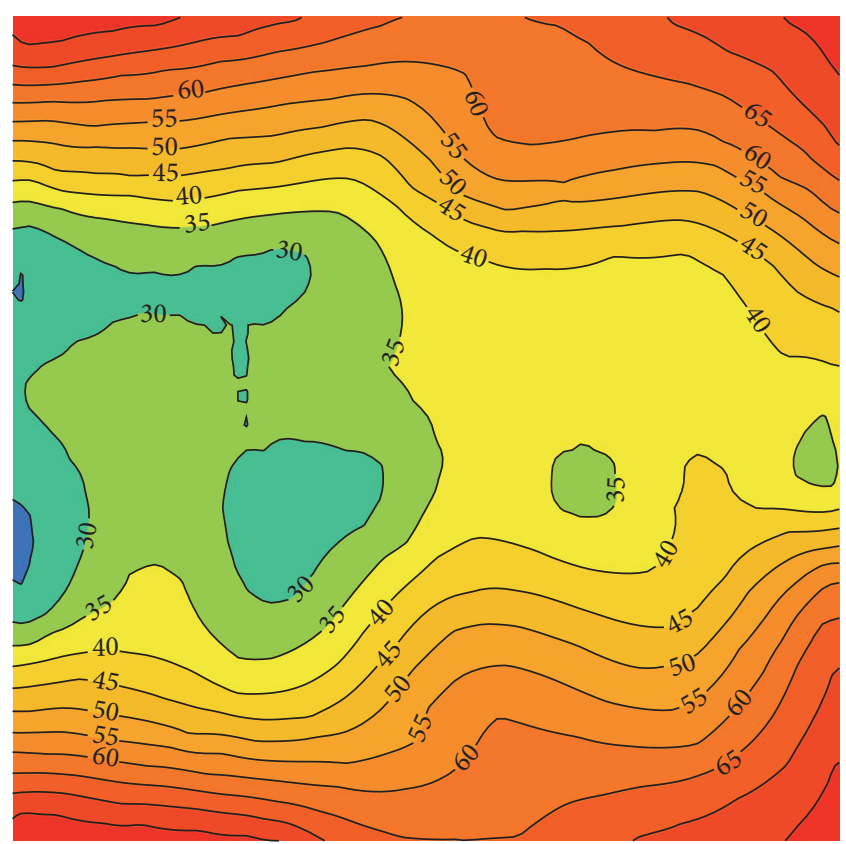

FIGURE 8: Oil saturation distribution after injecting 0.6 PV water through horizontal well.

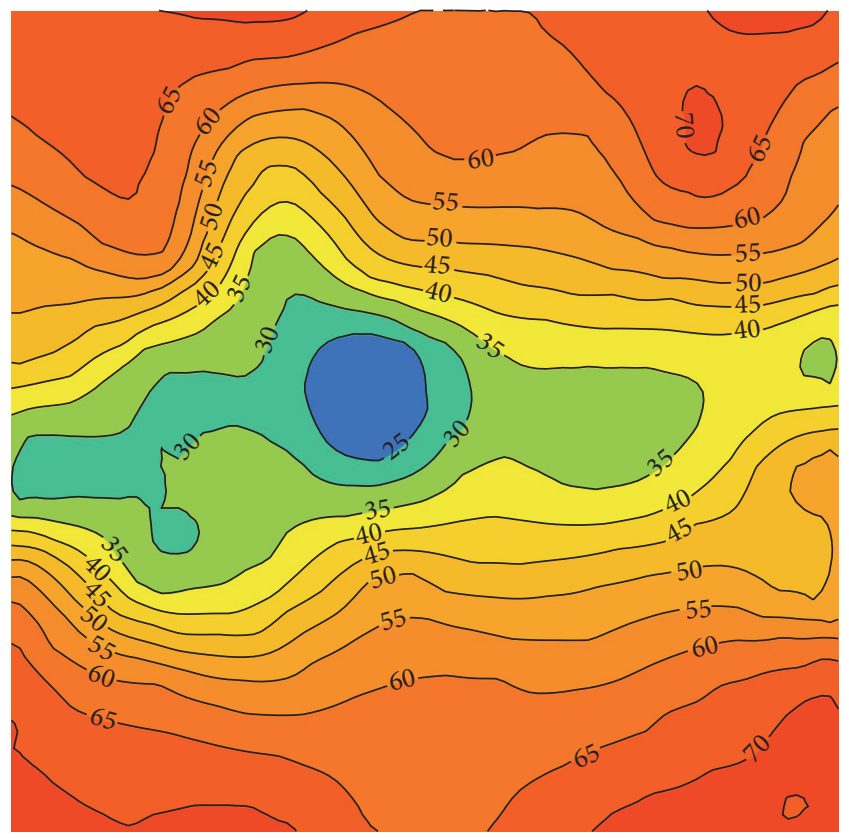

FIGURE 9: Oil saturation distribution after injecting 0.6 PV water through vertical well.

area by horizontal injection well is larger than that of vertical injection well by comparing oil and water saturation distribution. The seepage characteristics of two different injection well patterns are obviously different. When water is injected through vertical injection well, water flow is overall in radial direction and the sweep efficiency is poor. By injecting through horizontal well, the water flooding is very similar to parallel piston-like water flooding. It also possesses the 


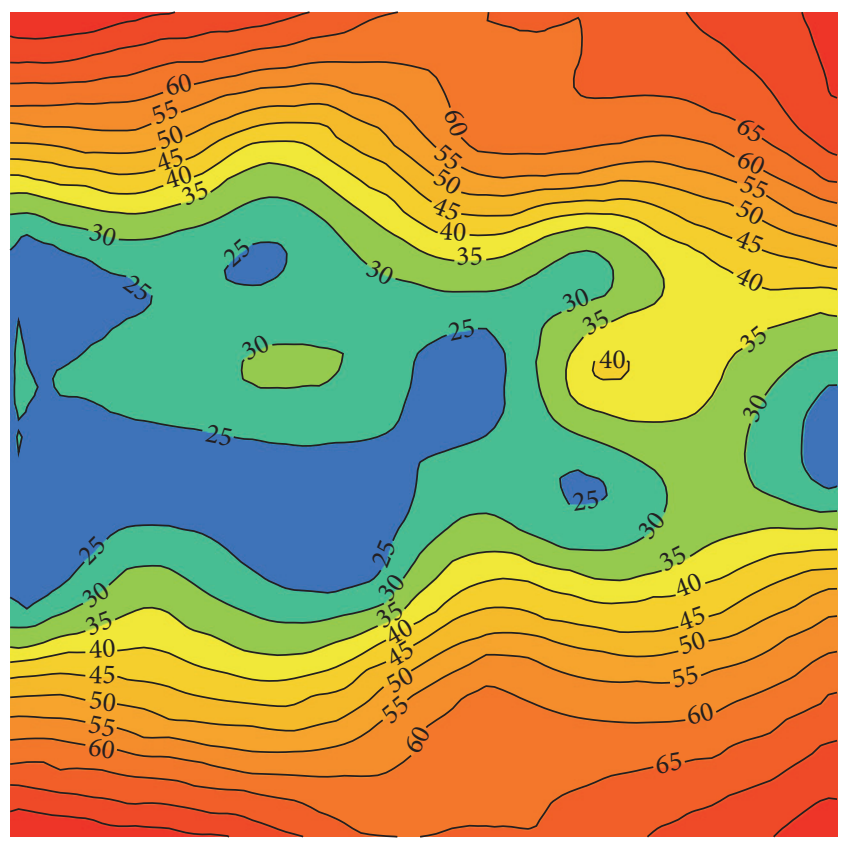

FIGURE 10: Oil saturation distribution at the end of water flooding by horizontal well.

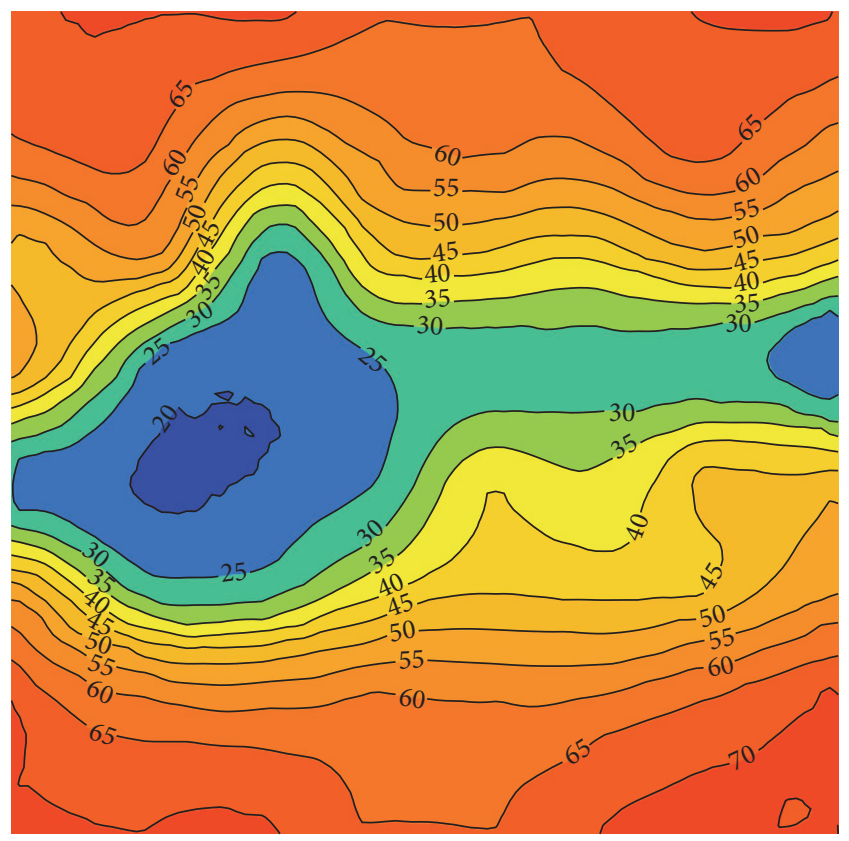

FIGURE 11: Oil saturation distribution at the end of water flooding by vertical well.

characteristics of radial flow pattern. As a combined effect, the sweep efficiency using horizontal injector is increased by $17.2 \%$, while horizontal injection well does not improve microscopic oil displacement efficiency.

3.2.2. The Gravity Effect on Water Flooding in Heavy Oil Reservoir. According to the similarity criteria, it is both sufficient and necessary to maintain laboratory and field
TABLE 5: The design of displacement pressure drop in five cases based on similarity criteria $\pi_{1}$.

\begin{tabular}{lc}
\hline Similarity criterion $\pi_{1}$ & Displacement pressure drop $\Delta P i / \mathrm{MPa}$ \\
\hline$\Delta \rho g H=\Delta P_{i}$ & 0.0012 \\
$\Delta \rho g H=\Delta P_{i} / 2$ & 0.0025 \\
$\Delta \rho g H=\Delta P_{i} / 4$ & 0.005 \\
$\Delta \rho g H=\Delta P_{i} / 8$ & 0.01 \\
$\Delta \rho g H=\Delta P_{i} / 16$ & 0.02 \\
\hline
\end{tabular}

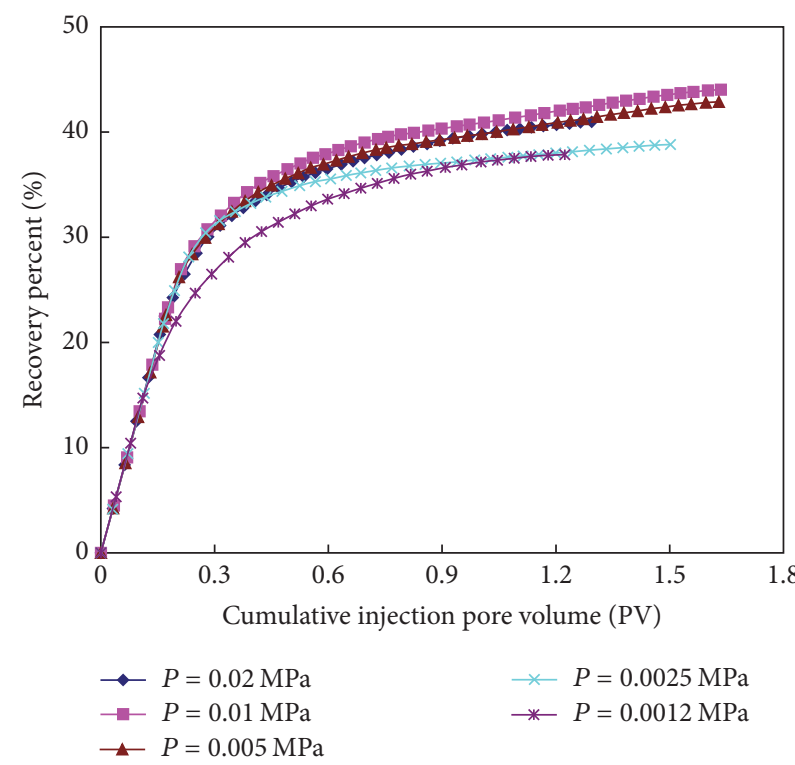

FIGURE 12: The relationship of oil recovery under different displacement pressure versus cumulative water injection volume.

similarity criteria $\left(\pi_{1}, \pi_{2}\right.$, and $\left.\pi_{3}\right)$ similar for water flood and it is also the basis for designing laboratory physical model parameters and performing physical simulation experiments. On the basis of keeping the similarity criterion $\pi_{2}$ (gravity and capillary force ratio) and $\pi_{3}$ (gravity and viscous force ratio), change the value of $\pi_{1}$ to optimize driving pressure, as shown in Table 5.

We have collected all five core flood results from 3D physical model experiments. The cumulative oil recovery profile with cumulative injection volume by varying the ratio of gravity to drive forces is presented in Figure 12. As seen in Figure 13, the ultimate oil recovery keeps changing by varying the ratio of gravity/driving force. With the ratio increasing, recovery factor firstly rises and then drops. When the gravity to driving force ratio is $1 / 8$, recovery factor reaches the highest.

There are two main reasons to explain the variation of recovery factor with the varying ratios. Firstly, when the ratio of gravity to driving force is large, displacement pressure is small. The gravity force becomes the main driving force, which might not be large enough to overcome the capillary force in the reservoir. Hence, the displacement effect in this case is poor. We also can conclude that gravity is important for heavy oil reservoir development, but it becomes unfavorable for oil production when the gravity is the major production 


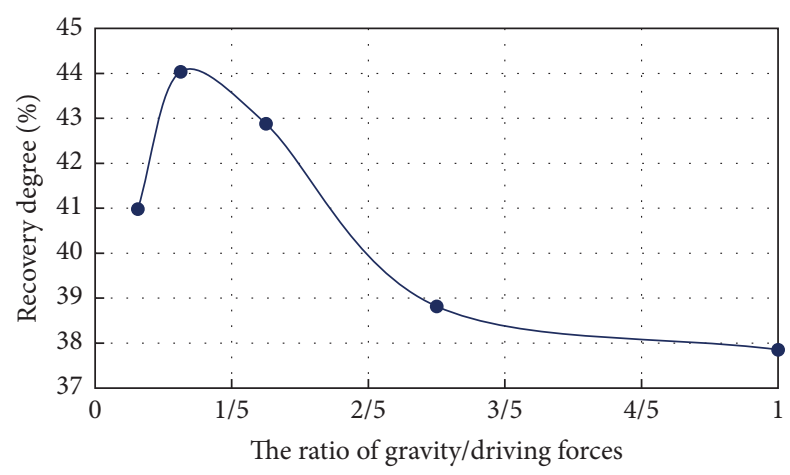

FIGURE 13: The relationship of recovery factor with the varying ratio of gravity/driving forces.

mechanism. Secondly, when the ratio of gravity and driving force is small, the driving force becomes large, which reduces the influence of gravity on oil recovery. In this scenario, the risk of early water breakthrough will increase; hence, the recovery factor is reduced. Therefore, it is very important to determine the optimal ratio of gravity to driving force (the displacement pressure). The results of our 3D physical model experiments have shown that the best gravity to driving force ratio is $1 / 8$.

Since the experimental model is two-dimensional planar model, the abovementioned experimental results cannot be directly applied to the reservoir scales. We should upscale the experimental results to the real reservoir dimensions based on similarity criteria. The object of this experiment is a quarter of the actual model unit. The reservoir thickness is $30 \mathrm{~m}$, and the well spacing is $70 \mathrm{~m}$. In order to exactly mimic the reservoir conditions and dimensions, the height of experimental model is $0.6 \mathrm{~m}$ and the well spacing is $140 \mathrm{~cm}$ determined by geometric similarity. However, in the actual experimental model, the well spacing is $5 \mathrm{~cm}$, which is only $1 / 28$ of the well spacing in the indoor model. As a result, the ratio of gravity to driving force in the oilfield should be from 14 to 28 times. The reservoir's gravity is $\Delta \rho g H=0.021 \mathrm{MPa}$; then, the production pressure difference is $\Delta P=(8 \times 14 \sim$ $8 \times 28) \Delta \rho g H$ in the oilfield, that $\Delta P$ is $2.352 \sim 4.704 \mathrm{MPa}$. Therefore, the optimal production pressure difference for the oilfield is $2.352 \sim 4.704 \mathrm{MPa}$.

\section{Conclusions}

(1) The water and oil saturation has been effectively monitored by measuring the electrical resistivity in physical model in real-time manner.

(2) Three dimensionless groups $\pi_{1}, \pi_{2}$, and $\pi_{3}$, which have the major impact on this design of physical simulation, have been derived. Sensitivity analysis showed that similarity criteria $\pi_{1}$ and $\pi_{2}$ have the great impact on the water flood using horizontal injector at the top of thick oil reservoir. And they are also the main factors to control the oil and water longitudinal distribution. In the actual experiment, permeability of model is selected to be 6 darcies and the crude oil viscosity is $583 \mathrm{mPa} \cdot \mathrm{s}$.

(3) Under the same conditions, compared to the vertical injection well, horizontal injection well improves reservoir sweep efficiency by $17.2 \%$ from the $3 \mathrm{D}$ physical model experiments. However, it cannot enhance oil displacement efficiency microscopically.

(4) There is an optimum ratio of gravity to driving force, where we can achieve the highest oil recovery. Specifically, in the experiment described in the paper, the optimum driving force is 8 times of gravity force.

(5) Based on the experimental results and dimensional analysis, we have calculated the optimal gravity force, which is $1 / 112-1 / 224$ times of production pressure differential under the actual oilfield conditions. The range of optimal production pressure differential is 2.352 4.704 MPa.

\section{Competing Interests}

The authors declare that there is no conflict of interests regarding the publication of this manuscript.

\section{Acknowledgments}

The authors would like to acknowledge the financial support from Natural Science Foundation Project (no. 51374221) and National Key Technology Research and Development Program (no. 2012BAC26B05) for this study.

\section{References}

[1] S. A. Hovanessian and F. J. Fayers, "Linear waterflood with gravity and capillary effects," Transactions of the AIME, vol. 222, pp. 32-36, 1961.

[2] A. B. Cunningham and P. R. Chaliha, "Field testing and study of horizontal water injectors in increasing ultimate recovery from a reservoir in thamama formation in a peripheral water injection scheme in a giant carbonate reservoir, United Arab Emirates," in Proceedings of the Abu Dhabi International Petroleum Exhibition and Conference, Paper SPE-78480, Abu Dhabi, United Arab Emirates, October 2002.

[3] M. Al Gharaib and R. C. Gharbi, "A comparative analysis of waterflooding projects using horizontal wells," in Proceedings of the Middle East Oil and Gas Show and Conference (MEOS '15), SPE-93743-MS, Manama, Bahrain, March 2015.

[4] H. Ferreira, D. D. Mamora, and R. A. Startzman, "Simulation studies of waterflood performance with horizontal wells," in Proceedings of the Permian Basin Oil and Gas Recovery Conference, Paper SPE-35208-MS, Midland, Tex, USA, March 1996.

[5] R.-Y. Cao, L.-S. Cheng, L.-W. Chai, X.-L. Li, and Z.-M. Jin, "Gravity assisted lateral horizontal well water flooding technology in heavy oil reservoir," Journal of Southwest Petroleum University (Science \& Technology Edition), vol. 30, no. 1, pp. 7073, 2008.

[6] J. T. Ding, "Gravity assisted lateral horizontal well water flooding experiment in Block G264," Inner Mongolia Petrochemical Industry, no. 21, pp. 30-31, 2011. 
[7] A. Belghache, S. Al-Hinai, A. Rabaani et al., "Challenges and learnings from thermal development of thick heavy oil reservoirs in Southern Oman," in Proceedings of the SPE EOR Conference at Oil and Gas West Asia, SPE-179812-MS, Muscat, Oman, March 2016.

[8] H. Zhang, T. Ge, M. Chen et al., "Field and numerical simulation study on stereoscopic network development at later cyclic steam at thick heavy-oil reservoir," in Proceedings of the SPE Asia Pacific Oil and Gas Conference and Exhibition, SPE-165921-MS, Jakarta, Indonesia, October 2013.

[9] R. Al Adawi, G. Rocco, S. Al Busaidi et al., "Seismic reservoir monitoring of a thermal EOR redevelopment; Thick heavy oil field in Oman," in Proceedings of the SPE Middle East Oil and Gas Show and Conference, SPE-164353-MS, Manama, Bahrain, March 2013.

[10] F. Arguelles-Vivas and T. Babadagli, "Analytical solutions and derivation of relative permeabilities for water-heavy oil displacement and gas-heavy oil gravity drainage under nonisothermal conditions," SPE Reservoir Evaluation \& Engineering, vol. 19, no. 1, pp. 181-191, SPE-179722-PA, 2016.

[11] K. Wu and J. E. Olson, "Simultaneous multifracture treatments: fully coupled fluid flow and fracture mechanics for horizontal wells," SPE Journal, vol. 20, no. 2, pp. 337-346, 2015.

[12] M. Mahmoudi, M. Roostaei, and A. Ghalambor, "Sand screen design and optimization for horizontal wells using reservoir grain size distribution mapping," in Proceedings of the SPE International Conference and Exhibition on Formation Damage Control, SPE-179036-MS, Lafayette, Louis, USA, February 2016.

[13] J. F. Berry, A. J. M. Little, and H. J. Salt, "In-situ saturation measurements improve analysis and interpretation of laboratory miscible and immiscible displacement processes," SPE Reservoir Engineering, vol. 6, no. 4, pp. 429-436, 1991.

[14] D. F. Brost and L. A. Davis, "Determination of oil saturation distributions in field cores by microwave spectroscopy," in Proceedings of the SPE Annual Technical Conference and Exhibition, SPE-10110-MS, San Antonio, Tex, USA, October 1981.

[15] G. Setser and M. R. Williams, "Measurement of remaining oil saturation in northern michigan using nuclear magnetism log data and pressure core," in Proceedings of the SPE Annual Technical Conference and Exhibition, SPE-14276-MS, Las Vegas, Nev, USA, September 1985.

[16] P. P. Shen, J. L. Wang, Y. L. Yian et al., "Saturation measurement technique for 3D reservoir physical modeling," Petroleum Exploration and Development, vol. 31, pp. 71-75, 2004.

[17] P. Van Meurs, "The use of transparent three-dimensional models for studying the mechanism of flow processes in oil reservoirs," Transactions of the AIME, vol. 210, pp. 295-301, 1957.

[18] Q. H. Tian, "Similar criteria in waterflooding thick oil pay zones and their application," Petroleum Geology \& Oilfield Development in Daqing, vol. 4, article 9, 1983. 


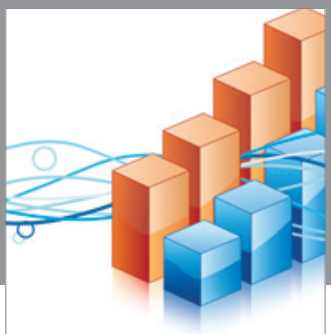

Advances in

Operations Research

vatem alat4

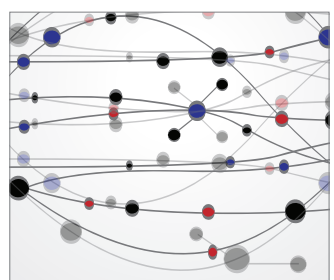

\section{The Scientific} World Journal
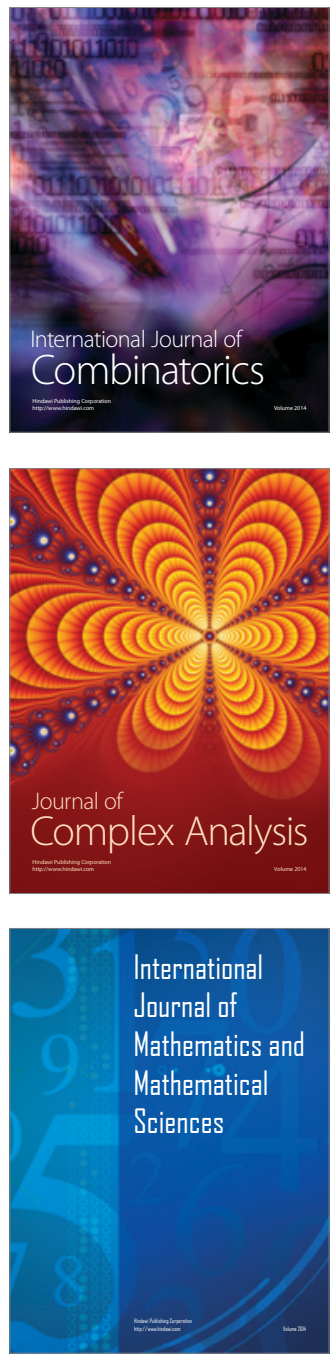
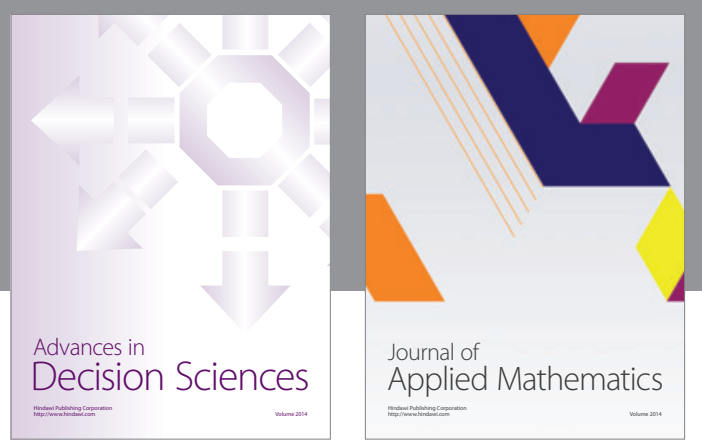

Algebra

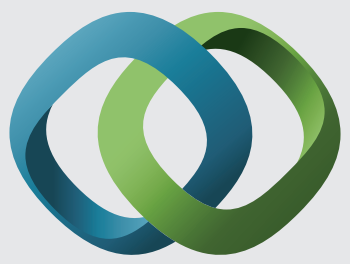

\section{Hindawi}

Submit your manuscripts at

http://www.hindawi.com
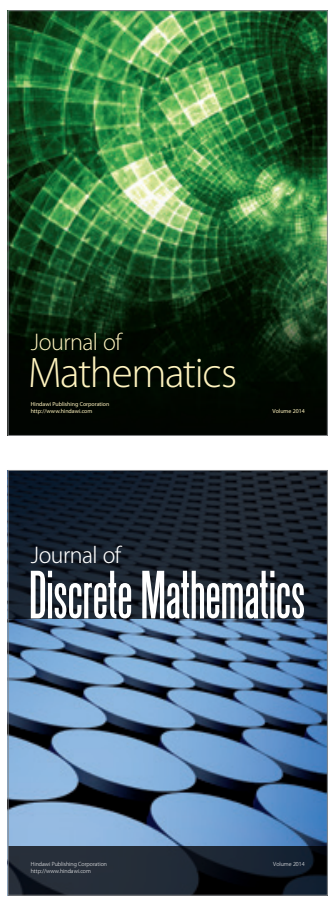

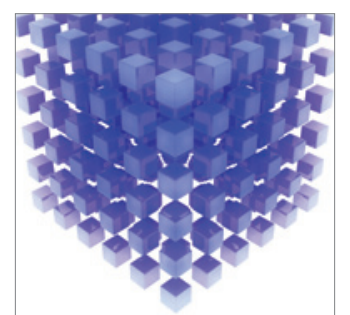

Mathematical Problems in Engineering
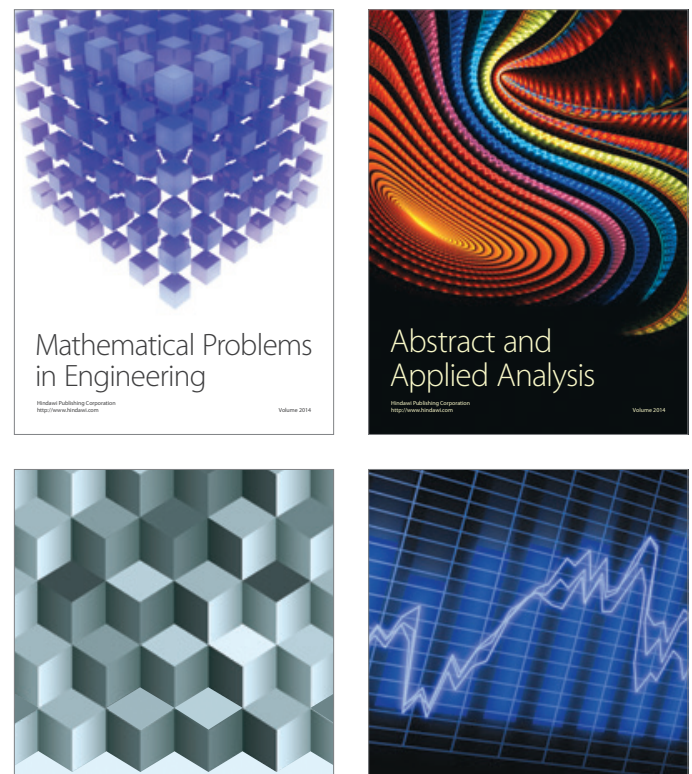

Journal of

Function Spaces

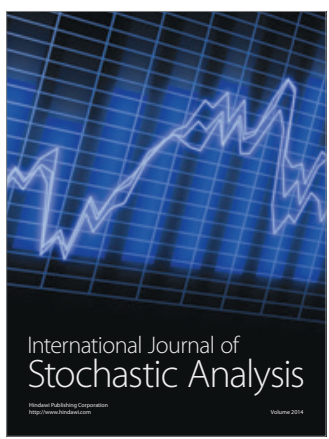

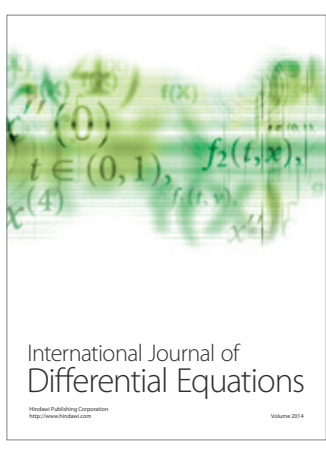
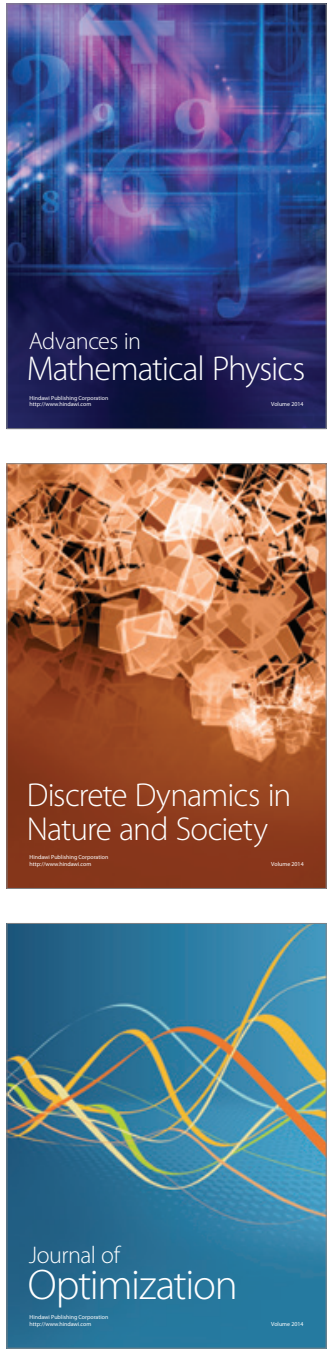